Siedlecki Zygmunt, Szafrańska Malgorzata, Główczewska-Siedlecka Emilia, Śniegocki Maciej. Horse riding - related injuries from the point of view of a neurosurgeon. Journal of Education, Health and Sport. 2022;12(1):274-282. eISSN 2391-8306. DOI http://dx.doi.org/10.12775/JEHS.2022.12.01.23

https://apcz.umk.pl/JEHS/article/view/JEHS.2022.12.01.023

https://zenodo.org/record/5907909

The journal has had 40 points in Ministry of Education and Science of Poland parametric evaluation. Annex to the announcement of the Minister of Education and Science of December 21, 2021. No. 32343. Has a Journal's Unique Identifier: 201159. Scientific disciplines assigned: Physical Culture Sciences (Field of Medical sciences and health sciences); Health Sciences (Field of Medical Sciences and Health Sciences).

Punkty Ministerialne z 2019 - aktualny rok 40 punktów. Zalącznik do komunikatu Ministra Edukacji i Nauki z dnia 21 grudnia 2021 r. Lp. 32343. Posiada Unikatowy Identyfikator Czasopisma: 201159. Przypisane dyscypliny naukowe:Nauki o kulturze fizycznej (Dziedzina nauk medycznych i nauk o zdrowiu); Nauki o zdrowiu (Dziedzina nauk medycznych i nauk o zdrowiu). () The Authors 2022;

This article is published with open access at Licensee Open Journal Systems of Nicolaus Copernicus University in Torun, Poland

Open Access. This article is distributed under the terms of the Creative Commons Attribution Noncommercial License which permits any noncommercial use, distribution, and reproduction in any medium, provided the original author (s) and source are credited. This is an open access article licensed under the terms of the Creative Commons Attribution Non commercial license Share alike. (http://creativecommons.org//icenses/by-nc-sa/4.0/) which permits unrestricted, non commercial use, distribution and reproduction in any medium, provided the work is properly cited.

Received: 02.01.2022. Revised: 17.01.2022. Accepted: 26.01.2022.

\title{
Horse riding - related injuries from the point of view of a neurosurgeon
}

Zygmunt Siedlecki ${ }^{1}$, Małgorzata Szafrańska ${ }^{2}$, Emilia Główczewska-Siedlecka ${ }^{3}$, and Maciej Śniegocki ${ }^{1}$

1. Department of Neurosurgery, Neurotraumatology and Pediatric Neurosurgery, Ludwik Rydygier Collegium Medicum in Bydgoszcz, Nicolaus Copernicus University in Toruń

2. Department of Endocrinology and Diabetology, Ludwik Rydygier Collegium Medicum in Bydgoszcz, Nicolaus Copernicus University in Toruń

3. Department of Geriatric, Ludwik Rydygier Collegium Medicum in Bydgoszcz, Nicolaus Copernicus University in Toruń

Corresponding address:

Dr. med. Zygmunt Siedlecki Department of Neurosurgery, Neurotraumatology and Pediatric Neurosurgery, the Ludwik Rydygier Collegium Medicum in Bydgoszcz,

ul. Skłodowskiej-Curie 9

85-094 Bydgoszcz

tel.: +48606302680

e-mail: siedlecki@cm.umk.pl 


\begin{abstract}
Horse riding (equestrianism) is a very old form of physical activity, and today it has become a very popular sport and recreation. Similarly to other sports, equestrianism carries potential risk of injuries, most often caused by a fall from a horse back. Horse riding can cause spine and brain injuries, which are treated by neurosurgeons. Both brain and spine injuries can potentially be life - threatening or cause severe disability. In our neurosurgical center, horse related injuries accounted for $7.69 \%$ of all sports - related injuries. We treated 4 girls in total: 3 with spinal injuries, 1 with brain injuries. Girls with spine injuries were treated conservatively, and girls with brain injuries - surgically. All patients had good prognosis. We have reviewed the literature about horse - related trauma. Literature showed that they occurred more often in young age patients and mainly in girls, which was consistent with our observations. Numerous authors emphasized the protecting role helmets. The authors emphasized the key role of education and proper care of coach. Although the literature described some fatal horse - related injuries, in our material all patients were healed and returned to a perfect clinical state.
\end{abstract}

Key words: horse riding, injury, sport, neurosurgery

\title{
Introduction
}

Horse riding (equestrianism) is a form of active leisure and sport. Horse riding is an outdoor activity, requires training and special clothing. Horse riding can be practiced in special squares called paddocks, as well as in forests, fields, and all places of landscape. It is one of the oldest sports known since ancient and prehistoric times, although then horseback riding was regular type of transport, and today it is recreation. For the beginning people domesticated horses, which happened around 3.5 thousand years BC [1,2]. The concept of horse riding as a sport was proclaimed in 1134 when the first Equestrian Academy in Italy was established [3]. Horseback riding also had a military aspect in recent times. Horsemanship was used in cavalry. Until the 18th century, Polish horse riding was considered one of the best in the world [4].

In the nineteenth century, Polish horse riding was restricted by the invaders and this sport could develop in Poland only after the First World War [5]. Another war and the post - war periods in Poland, associated with the The Second World War and than with communists stopped the development of equestrianism again, and this sport began to develop after 1989 [6].

Equestrianism became an Olympic discipline in 1900 and is until the present day [7]. There are different equestrian disciplines. The basic is classic horse riding, which consists of several disciplines: dressage, show jumping and a comprehensive riding horse competition [6,7]. Horse riding is very popular. According to the Polish Equestrian Federation (pol. Polski Związek Jeździecki, PZJ), there are about 30,000 active riders in Poland, while about 300,000, i.e. ten times more, ride incidentally and periodically on horseback [8]. There are about 400 equestrian clubs associated in the PZJ in Poland. According to demographic data, horse riding in Poland is popular in every region [8,9]. In the Kuyavian - Pomeranian Voivodeship (region of the manuscript authors), according to the Statistical Yearbook in 2016, 456 people trained horse riding, 33 sports sections were registered, there were also 19 coaches and 46 sports instructors [9].

Horse riding carries a risk of injuries, which is no different from any other sport and leisure activity. Reports of horse riding injuries in the literature are described in the discussion of this manuscript. Injuries as a consequence of horse riding are most often associated with falling from a horse, which is the same as falling from a height. The average horse's back is approximately 1.6 meters above ground level, and the rider's geometric center of gravity is approximately 2 meters above the ground [9]. Injuries treated in neurosurgical departments concern the brain and spine / spinal cord. According to neurosurgical statistics, falls from a height are the second most frequent cause of serious injuries after car accidents [10]. Both brain and spine injuries are potentially 
severe. Department of Neurosurgery in Medical College in Bydgoszcz of Nicolaus Copernicus University in Torun (Poland) is a trauma center established by the polish and voivodship government, where patients with serious injuries are transported, including sport, physical activity and tourism - related injuries.In the Kuyavian - Pomeranian Voivodeship, with capital in Bydgoszcz, as indicated above, horseback riding is practiced by almost 500 people [9].

The aim of this manuscript was to analyze how often injuries sustained as a result of the sport of horse riding are of interest to the neurosurgeon and to analyze:

1. What injuries occur more often: the brain or the spine?

2. What is the most common neurosurgical treatment: conservative vs surgical?

3. What is the prognosis?

4. Do horse riding injuries account for a large proportion of sport - related neurosurgical injuries?

\section{Material \& methods}

The study involved four patients with horse - related injuries, all of whom were treated in our neurosurgical department in 2017 - 2020. As indicated above, University Hospital No. 1 in Bydoszcz, Poland, as part of the Medical College of Nicolaus Copernicus University, is a government -established trauma center for the entire Kuyavian - Pomeranian Voivodeship, so most horse riding - related injury patients in this region are brought to our center for treatment. The Kuyavian-Pomeranian Voivodeship has a population of over 2 million.

All patients were admitted urgently to hospital. Three patients were referred from emergency departments of smaller hospitals after the diagnosis of injury on the basis of computed tomography (CT). One patient was brought by an ambulance directly from the paddock. All patients treated in our neurosurgical department were young women, as presented in Table 1.

Patients with horse - related injuries $(n=4)$ accounted for $0.32 \%$ of all patients admitted in 2017 - 2020 with brain and spine injuries $(n=1236)$ and $7.69 \%$ of all sport - related injuries $(n=52)$ in our department.

Table 1. Patients with horse -related trauma treated in our department

\begin{tabular}{|l|l|l|l|l|l|l|}
\hline type of injury & amount & $\begin{array}{l}\text { anatomical } \\
\text { region }\end{array}$ & age & gender & GCS* & VAS** \\
\hline spine fracture & 3 & L1, L1, L3 & $8,12,13$ & females & $15,15,15$ & $8,7,10$ \\
\hline $\begin{array}{l}\text { skull fracture and } \\
\text { intracranial } \\
\text { bleeding }\end{array}$ & 1 & $\begin{array}{l}\text { temporal } \\
\text { region, }\end{array}$ & 18 & female & 13 & 10 \\
\\
* - Glasgow Coma Scale, ** - Visual Analogue Scale (pain measurement)
\end{tabular}

\section{Results}

1. Spine fractures

In the analyzed time period, 3 described girls were hospitalized after falling onto their backs from a horse. The falls took place during training in the paddock. During the fall, the girls experienced direct force by hitting the thoracic - lumbar region. Compression fractures of the vertebral bodies L1 $(n=2)$ and L3 $(n=1)$ were visualized in CT. These fractures did not cause spinal stenosis or any pressure on the nerve structures. The girls did not present any neurological disorders (no radicular pain, no paresis). The only symptom was pain. In order to classify fractures, the commonly used AO (ger. Arbeitsgemeinschaft für Osteosynthesefragen) assessment was adopted. The spine fracture classification system used in our center was developed by AO - Spine. AO - Spine is the leading global academic community for innovative education and research in spine care, inspiring lifelong learning and improving patients' lives. According to the AO - Spine, all girls presented A1 fracture types, which means compression fracture involving a single endplate withoutinvolvement of the posterior wall of the vertebral body. 
The treatment of choice, especially in young people with A1 spine fractures, is conservative treatment - immobilization with a corset. The treatment of choice, especially in young people with A1 spine fractures, is conservative treatment - immobilization with a corset. Due to the young age and the risk of potentially toxic and ionizing X-rays, control MRI (not CT) was performed. It visualized no pathologically high signal from the body, and the treatment was considered complete. An additional argument to avoid CT of the spine, apart from the above mentioned, was the fact that the morphology of the fractures in all three girls proved that A1 fractures (AO - Spine) predicted healing from the very beginning. From a neurosurgical point of view, these were favorable looking fractures. It proves what is contained in the conclusions of this manuscript that fractures of the spine as a result of a fall from a horse are not usually dangerous and did not require surgical treatment in our center.

Since CT of the spine fractures concerned underage patients, and the bioethics consent has allowed the publication of images of people over 18 years, no CT images with the above - described spine fractures were presented in this manuscript.

2. Skull and brain injury

In the studied material in our center, we treated one patient with a craniocerebral trauma. She was 18 - year - old girl. The girl fell and the horse kicked her in the head, traumatizing her with cranial blunt trauma. The protective toque was dislocated and therefore the temporal area on the head was exposed. The girl was admitted to the hospital, and CT showed temporal bone fracture with epidural hematoma under the fracture fissure as shown in Figure 1.

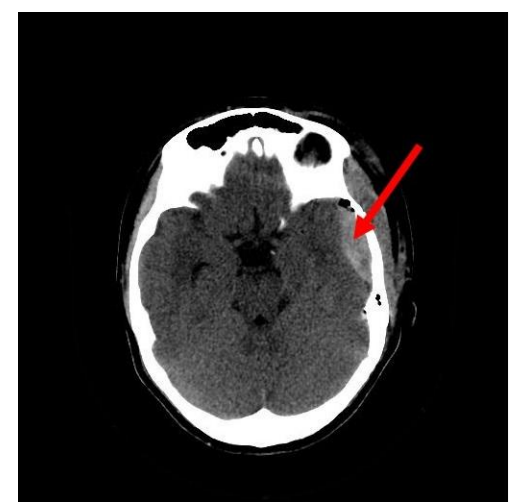

Figure 1. Head CT: epidural hematoma (marked with a red arrow)

The patient was 13 GCS as shown in Table 1. There were no paresis, aphasia, epileptic seizures. The patient was qualified for urgent surgical treatment. A craniotomy was performed with the removal of the hematoma, the broken fragments of the temporal bone were repositioned and fixed with titanium fixators. Early bedside rehabilitation was implemented after the operation. The girl was discharged home in a very good general condition, with no negative consequences in her neurological and functional condition.

\section{Discussion}

Horse riding injuries are widely covered in the literature and there are numerous references to it. Google Scholar reports 215,000 results after querying "horse related injuries". The authors reviewed the literature on this subject with particular emphasis to head and spine injuries, i.e. those that are of interest to neurosurgery.

References from 1973 - 2020 have been found. Despite the widespread use of horses in the past centuries, it was no publication about injuries associated with horses as sports injuries until 1973. This may mean that horse riding became a sport during second half of the 20th century and therefore reports of sport related injuries can be found. 
Barber (1973) emphasized that during the period of publication of his report, equestrianism became popular. Between 1971 and 1972, he noted over 150 patients with horse-related injuries that were severe enough to advanced medial care [11]. According to author horse riding related injuries were more frequent and more serious than commonly believed [11]. He noted that supervision of children was often insufficient and helmet and clothing were inappropriate [11]. Based on Barber's report and own experience, it is necessary to put special attention to children supervision while practicing horse riding.

Gierup (1976) estimated that $66 \%$ of horse riding injuries concerned children. This is consistent with our observations, as all the patients described in our study were children or adolescents. Author described one fatal accident, and 11\% were diagnosed with brain trauma. 17\% of patients required surgery under general anesthesia [12]. He emphasized that many of the serious injuries could possibly have been avoided by using better safety equipment [12].

Ingemarson (1989) carried out analysis of horse related injuries resulting in the years 1669 - 1982 [13]. He noted 53 fatal equestrian injuries. He also emphasized that craniocerebral injuries dominated among the fatalities [13]. He stressed the importance of properly protecting helmets. In his study predominant gender among the victims was the female gender before the age of 25 [13], which is epidemiologically consistent with our study.

Bixby-Hammett (1990) calculated that brain injuries were the third most common type of horse related injury and can have potentially serious consequences [14]. He emphasized that no horse is a safe horse [14]. Some are safer than others, , but the horse is always a potentially lethal animal [14]. Prevention of accidents and injuries depends on the knowledge obtained earlier from the study of horse activity and biology [14]. According to Bixby-Hammett, education about safe practice of this sport discipline was also important.

Hamilton et al. (1993) prepared overview of 156 horse accidents that occurred in southern Alberta over a period of 6 years and resulted in nervous system injury, including 11 deaths. Most $(81 \%)$ of the accidents occurred during recreational activities and were related to a fall off the horse back [15]. Head injury occurred in $92 \%$ of patients and was responsible for all 11 deaths. Spine injury occurred in $13 \%$ of patients and was associated with head injury in $40 \%$ [15]. In Hamilton's material, one peripheral nerve injury was identified. Author noted that the helmets were used by only two victims [15]. The 11 deaths resulting from severe head trauma accounted for $79 \%$ of all horse riding deaths [15]. According to author, this profile of neurological injuries related to horse-related accidents argues for the need for protective helmet [15]

Christey et al. (1994) estimated that horse riding injuries accounted for approximately 2,300 hospitalizations per year among under-25s in the United States, but injury rates, injury patterns, and risk factors in this population were not well studied at the time of publication of his manuscript [16]. Riding injuries among participants in his study were usually serious [16]. The author emphasized that general physicians should inform their horse riding patients about the dangers and emphasize the use of helmets. Autor showed [16] that, as in our work, horse riding injuries occur in young people.

Ghosh et al. (2000) conducted a retrospective analysis of 315 patients registered in the National Register of Child Injuries from February 1995 to August 1999. According to his study $62 \%$ of the 315 patients were girls [17]. The median age was 10 years. $65 \%$ of patients were injured while riding, and the most common mechanism of injury was falling off the horse back [17]. Bone fractures were the most common, followed by head injuries. According to the author, the most frequently injured anatomical sites were head, neck and face, then the upper limb, abdomen, and then the lower limb[17]. The median period in hospital was 2 days. $40 \%$ of patients required treatment in an intensive care unit with an average length of stay of 2 days. 39\% of patients underwent surgery [17]. The Injury Severity Score (ISS) ranged from moderate to critical in $31.5 \%$ of the children. There were 8 deaths, $2.5 \%$ injured children [17]. Head injuries were the most common cause of death. Of the 307 survivors, $3 \%$ were discharged to a rehabilitation center, 
and $2 \%$ of children had 1 or more functional disorders lasting more than 7 months after discharge[17] . Based on these results, author concluded that horse - related injuries are common in children and can cause severe injuries leading to death and long - term disability [17].

Holland et al. (2001) assessed the spectrum and effects of horse -related injuries in children admitted to Children's Hospital Westmead (CHW) from January 1988 to December 1999, John Hunter Children's Hospital (JHCH) January 1991 to December 1997, and deaths reported to New South Wales Pediatric Trauma Death Registry (NPTD) January 1988 to December 1999. He [18] took into account the circumstances of the injury in his analysis; helmet use and adult supervision. In his material, 232 children was admitted with horse - related injuries: 97 to CHW at 12 years and 135 to JHCH at 7 years, with one death at each hospital[18]. Six deaths have been reported to the NPTD registry over a 12-year period. The median age was 11 years (range 1-17). Girls accounted for $65 \%$ of the injured, and $75 \%$ of the children were injured while riding [18]. Falls caused injuries in $76.3 \%$ of the cases. Head and upper limb injuries accounted for 216 injuries (73\%). Five out of six children died with severe head injuries. In the CHW group, the use of a helmet was documented only in 24 riders (38\%), and adult supervision in $22(22.9 \%)$ [18]. Horse - related trauma accounted for a significant number of deaths and injuries in children in NSW [18]. The author emphasized that the use of approved helmet for horse activities could reduce the severity of head injuries.

Silver (2002) assessed that among horse riding injuries, serious injuries to the nervous system are the most dangerous. He analyzed 11 articles and data obtained from the Stoke Mandeville, Oswestry and Odstock spine unit survey and internet searches to determine the nature of these injuries [19]. According to Silver, head injuries exceeded the number of spine injuries five to one. Unlike other sports accidents, there are more lumbar and thoracic injuries than cervical injuries, and more women are injured than men, consistent with our analysis. Silver emphasized that, of all activities related to horse riding, jumping most likely causes back injury [19].

Jagodzinski et al. (2005) assessed that horse riding is an increasingly popular activity among today's youth, giving them the opportunity to learn responsibility and respect for animals. However, it can cause serious injuries. According to Jagodzinski equestrian injuries ranked second after car accidnts and scored higher than all injuries related bicycles [20]. The author emphasized that hoof injuries in non - riding children accounted for approximately $30 \%$ of all horse - related injuries and could have resulted in more serious medical condition [20]. This is consistent with our observation, because among the patients described in our study, the girl who suffered a hoof injury was in the most severe clinical condition and she was the only one who required surgical treatment (intracranial hematoma evacuation with brain decompression).

Carrillo et al. (2007) stressed that, according to the Centers for Disease Control and Prevention (CDC), approximately 30 million people have ridden horses each year in the United States. According to him, horse riding injuries resulted in 50,000 visits to emergency units [21]. He stressed that the popularity of recreational horse riding in South Florida had increased, and that the incidence of horse - related injuries was a reflection of this. He reviewed patients admitted to the state level I trauma center who sustained horse riding injuries between January 2000 and December 2003. Author identified 27 patients $(12 \mathrm{M}, 15 \mathrm{~F})$. The average age was 36 . The injuries occurred during recreational horse riding [21]. Multiple serious injuries have been documented in 24 patients. All patients required hospitalization with an average stay of 5 days. Five patients had a positive toxicology test on admission. No deaths were documented in this review. Author assessed that horse riding injuries can be serious, and that alcohol and drugs can exacerbate these injuries [21].

Lin et al. (2011) retrospectively reviewed 121 cases of horse riding spinal cord injury (SCI) in the National SCI Statistical Center database from 1973 to 2008. He compared the number of injuries, gender, age and type of SCI in horse riding with other sports and activities. In the group of horse riders, the level of preserved neurological function, completeness of SCI, American Spinal 
Injury Association (ASIA) classifications and the use of mechanical ventilation at discharge were examined. According to his data, mean age of the injury was 37.8 years $( \pm 15.2)$ [22]. Most of the patients were white $(88 \%)$ and female $(50.4 \%)$. Compared to diving, motorcycle riding, football and gymnastics, horse riding was significantly more frequent $(\mathrm{p}<0.005)$, with a higher mean age of injury, and an equal likelihood of paraplegia and tetraplegia [22]. The most common levels of conserved neurological function were C4-C6, Th12, and L1. Horse riding injuries most often resulted in incomplete tetraplegia (41\%) followed by complete paraplegia (24\%) [22]. Only 4 patients required mechanical ventilation after discharge from acute inpatient rehabilitation. According to author equestrian spinal cord injury affects an equal proportion of men and women, has a wide age range and most often leads to incomplete tetraplegia followed by complete paraplegia[22]. Research findings increase awareness of the demographic and neurological outcomes of SCI survivors during horse riding and could help drive future research assessing SCI mechanisms in equestrian riders to improve injury prevention and management [22].

Acton et al. (2020) performed a retrospective analysis of horse - related injuries in 1990-2017. This analysis was performed with the use of the National Electronic System for the Supervision of Injuries (NEISS). Cases were identified with the code NEISS 1239 (horseback riding: activity, clothing or equipment). The analyzes performed included the calculation of national injury estimates, relative risk (RR) with 95\% confidence intervals (CI), and linear regression [23]. The author found that from 1990 to 2017 , approximately $1,836,536(95 \% \mathrm{CI}$ : $1,494,788-2,178,284)$ people reported to emergency departments in the United States with horse related injuries [23]. The annual injury rate decreased by $30.8 \%$ from 1990 to 1996, increased by $33.0 \%$ from 1996 to 2000, and then decreased by 46.0\% from 2000 to 2017 [23]. Among older adults over the age of 60 , the annual injury rate increased by $139.6 \%$ during the study period. The number of diagnoses of concussion and closed head injuries increased by $337.2 \%$ from 1990 to 2009. The most frequently injury mechanism was a fall (73.9\%), and the most frequently installed mechanism was kicking (42.1\%) [23]. Injuries at the assembly site led to hospitalization more often than injuries at the assembly site (RR 2.10, 95\% CI: 1.59-2.77) [23]. Author noted that despite the recent decline in horse - related injuries, these injuries are still common [23].

Naef et al. (2022) confirmed that more young females participating in equestrian sports attended emergency department than males which is consistent with our results on gender differences. According to Naef, the leading cause of equestrian injury was falling from a horse $(80.2 \%)$ [24]. In his study, orthopedic injuries accounted for approximately $60 \%$ of all lesions reported, and brain and head injuries approximately 30\% [24]. More than half of the injured children required hospitalization and almost $50 \%$ of them underwent surgery [24]. Naef observed one fatal outcome due to severe TBI. Riding injuries, Naef concluded, are more common and more serious than many other sports [24].

\section{Conclusions}

Horse - related injuries are relatively rare and account for approximately $7 \%$ of sports related trauma. Based on our experience and literature review, they mainly concern mainly female children and adolescents. Although the prognosis of all patients in our material was good, some authors report fatal injuries caused by horse riding. So knowing that injuries are potentially serious is key. Although in our material spine injuries dominated and the majority of patients were treated conservatively, it should be emphasized that some authors reported severe brain injuries requiring surgery and intensive therapy as not exceptional. Proper instructor care, training, education as well as clothing and equipment play an important role in the injuries prevention. 
Conflicts of interest - The authors declare that they have no conflict of interest.

\section{References:}

1. Kobryn, H. (1999). O pochodzeniu i udomowieniu konia. Koń Polski, 34(03), 24-26.

2. Pietrzyk, K., Ryszka, M., Musial, J., Niezgodzka, M., Solawa, J., \& Stefaniuk, M. (2014). Historia udomowienia-czyli kronika pisana kopytem. Konie i Rumaki, (07).

3. Anthony, D., Telegin, D. Y., \& Brown, D. (1991). The origin of horseback riding. Scientific American, 265(6), 94-101.

4. Czarnecki, J. R. (2014). The Polish cavalry: Horsemen in the age of armor. St. John's University (New York).

5. Nitze, R. A. (2006). " With swords and lances..." A study of Polish cavalry and how they fought German tanks during the September campaign 1939 (Doctoral dissertation, The Ohio State University).

6. Skulicz, B. (2012). Polskie jeździectwo na Igrzyskach Olimpijskich w okresie międzywojennym. Koń Polski, 47(07).

7. De Haan, D., \& Dumbell, L. C. (2016). Equestrian Sport at the Olympic Games from 1900 to 1948. The International Journal of the History of Sport, 33(6-7), 648-665.

8. Ozga, J. (2019). Jeździectwo-polski sport narodowy. Prawda czy fikcja?. Konie i Rumaki, (10).

9. Kozak, M. W. (2017). Making trails: Horses and equestrian tourism in Poland. In Equestrian Cultures in Global and Local Contexts (pp. 131-152). Springer, Cham.

10. Kumar, R., Lim, J., Mekary, R. A., Rattani, A., Dewan, M. C., Sharif, S. Y., ... \& Park, K. B. (2018). Traumatic spinal injury: global epidemiology and worldwide volume. World neurosurgery, 113, e345-e363.

11. Barber, H. M. (1973). Horse-play: survey of accidents with horses. Br Med J, 3(5879), 532-534.

12. Gierup, J., Larsson, M., \& Lennquist, S. (1976). Incidence and nature of horse-riding injuries. A one-year prospective study. Acta Chirurgica Scandinavica, 142(1), 57-61.

13. Ingemarson, H. A. N. S., Grevsten, S. V. E. N., \& Thorén, L. A. R. S. (1989). Lethal horse-riding injuries. The Journal of trauma, 29(1), 25-30.

14. Bixby-Hammett, D., \& Brooks, W. H. (1990). Common injuries in horseback riding. Sports Medicine, 9(1), 36-47.

15. Hamilton, M. G., \& Tranmer, B. I. (1993). Nervous system injuries in horseback-riding accidents. The Journal of trauma, 34(2), 227-232.

16. Christey, G. L., Nelson, D. E., Rivara, F. P., Smith, S. M., \& Condie, C. (1994). Horseback riding injuries among children and young adults. Journal of family practice, 39(2), 148-152.

17. Ghosh, A., DiScala, C., Drew, C., Lessin, M., \& Feins, N. (2000). Horse-related injuries in pediatric patients. Journal of pediatric surgery, 35(12), 1766-1770

18. Holland, A. J., Roy, G. T., Goh, V., Ross, F. I., Keneally, J. P., \& Cass, D. T. (2001). Horse-related injuries in children. Medical journal of Australia, 175(11-12), 609-612.

19. Silver, J. R. (2002). Spinal injuries resulting from horse riding accidents. Spinal cord, 40(6), 264-271.

20. Jagodzinski, T., \& DeMuri, G. P. (2005). Horse-related injuries in children: a review. WMJ: official publication of the State Medical Society of Wisconsin, 104(2), 50-54.

21. Carrillo, E. H., Varnagy, D., Bragg, S. M., Levy, J., \& Riordan, K. (2007). Traumatic injuries associated with horseback riding. Scandinavian journal of surgery, 96(1), 79-82.

22. Lin, C. Y., Wright, J., Bushnik, T., \& Shem, K. (2011). Traumatic spinal cord injuries in horseback riding: a 35-year review. The American journal of sports medicine, 39(11), 2441-2446. 
23. Acton, A. S., Gaw, C. E., Chounthirath, T., \& Smith, G. A. (2020). Nonfatal horse-related injuries treated in emergency departments in the United States, 1990-2017. The American journal of emergency medicine, 38(6), 1062-1068.

24. Naef, S., Steiger, C. N., Tabard-Fougère, A., Dayer, R., \& Ceroni, D. (2022). Epidemiological study of equestrian trauma in Geneva. Journal of Pediatric Orthopaedics, 42(2), e126-e131. 